\title{
Low Serum 25-Hydroxyvitamin D Levels Are Related to Frailty and Sarcopenia in Patients with Chronic Liver Disease
}

\author{
Chisato Saeki ${ }^{1,2, *(\mathbb{D}}$, Tomoya Kanai ${ }^{1,2}$, Masanori Nakano ${ }^{1,2}$, Tsunekazu Oikawa ${ }^{1}$, \\ Yuichi Torisu ${ }^{1,2}$, Masayuki Saruta ${ }^{1}$ and Akihito Tsubota ${ }^{3, * \mathbb{D}}$ \\ 1 Division of Gastroenterology and Hepatology, Department of Internal Medicine, The Jikei University School \\ of Medicine, 3-25-8 Nishi-shimbashi, Minato-ku, Tokyo 105-8461, Japan; tomoyaaust@hotmail.com (T.K.); \\ masanori-nakano@jikei.ac.jp (M.N.); oitsune@jikei.ac.jp (T.O.); torisu@jikei.ac.jp (Y.T.); \\ m.saruta@jikei.ac.jp (M.S.) \\ 2 Division of Gastroenterology, Department of Internal Medicine, Fuji City General Hospital, \\ 50 Takashima-cho, Fuji-shi 417-8567, Shizuoka, Japan \\ 3 Core Research Facilities, Research Center for Medical Science, The Jikei University School of Medicine, \\ 3-25-8 Nishi-shimbashi, Minato-ku, Tokyo 105-8461, Japan \\ * $\quad$ Correspondence: chisato@jikei.ac.jp (C.S.); atsubo@jikei.ac.jp (A.T.); Tel.: +81-3-3433-1111 (C.S. \& A.T.)
}

Received: 5 November 2020; Accepted: 11 December 2020; Published: 12 December 2020

\begin{abstract}
Low vitamin D status is related to frailty and/or sarcopenia in elderly individuals. However, these relationships are unclear in patients with chronic liver disease (CLD). This study aimed at exploring the relationship between serum 25-hydroxyvitamin D [25(OH)D] levels and frailty or sarcopenia in 231 patients with CLD. Frailty was determined based on five factors (weight loss, low physical activity, weakness, slowness, and exhaustion). Sarcopenia was diagnosed by applying the Japan Society of Hepatology criteria. The patients were classified into three groups according to baseline 25(OH)D levels: low $(\mathrm{L})$, intermediate $(\mathrm{I})$, and high $(\mathrm{H})$ vitamin $\mathrm{D}(\mathrm{VD})$ groups. Of the 231 patients, $70(30.3 \%)$ and $66(28.6 \%)$ had frailty and sarcopenia, respectively. The prevalence rate of frailty and sarcopenia significantly increased stepwise with a decline in the vitamin D status. The L-VD group showed the highest prevalence rates of frailty and sarcopenia (49.1\% (28/57), $p<0.001$ for both), whereas the H-VD group showed the lowest prevalence rates of frailty $(15.3 \%$ $(9 / 59))$ and sarcopenia $(18.6 \%(11 / 59))(p<0.001$ for both). Multivariate analysis identified serum $25(\mathrm{OH}) \mathrm{D}$ levels as a significant independent factor related to frailty and sarcopenia. Serum $25(\mathrm{OH}) \mathrm{D}$ levels significantly correlated with handgrip strength, skeletal muscle mass index, and gait speed. In conclusion, low serum vitamin D level, especially severe vitamin D deficient status, is closely related to frailty and sarcopenia in patients with CLD.
\end{abstract}

Keywords: chronic liver disease; sarcopenia; frailty; vitamin D

\section{Introduction}

Sarcopenia, characterized by a generalized decline of skeletal muscle mass and strength, is a serious complication in patients with chronic liver disease (CLD) [1,2]. Frailty is defined as increased vulnerability to stressors due to multisystem physiological impairment and is associated with, but not equivalent to, sarcopenia [3-5]. Sarcopenia and frailty negatively impact the quality of life, resulting in disability, and increase the risk of institutionalization and mortality [5-9]. In general, poor nutritional status, including low levels of branched-chain amino acids (BCAAs), vitamin D, zinc, and long-chain omega-3 fatty acids, is considered one of the causes of sarcopenia and frailty $[10,11]$. Therefore, 
nutritional evaluations and early therapeutic interventions for these disorders are imperative in patients with CLD.

The liver plays a crucial role in the metabolism of vitamin $\mathrm{D}$, which is included in a group of fat-soluble secosteroids. Vitamin $\mathrm{D}_{3}$ (cholecalciferol) and $\mathrm{D}_{2}$ (ergocalciferol) are synthesized in the skin under ultraviolet exposure and ingested from the diet and/or supplements. These two vitamin D forms are inactive until they are hydroxylated in the liver to form 25-hydroxyvitamin $\mathrm{D}$ [25(OH)D]. $25(\mathrm{OH}) \mathrm{D}$ is the main circulating form of vitamin $\mathrm{D}$ and is used as a representative biomarker of a person's vitamin D status. Subsequently, 25(OH)D undergoes further hydroxylation in the kidneys to form active 1,25-dihydroxyvitamin $\mathrm{D}[1,25(\mathrm{OH}) \mathrm{D}]$ [12]. Therefore, a reduction in circulating vitamin $\mathrm{D}$ levels reflect an impaired liver function or malnutrition. In addition, bile production is impeded in patients with CLD, leading to decreased fat absorption, and consequently, impaired uptake of vitamin $\mathrm{D}$ [13]. Accordingly, patients with CLD are frequently accompanied by low vitamin D status; vitamin D deficiency ( $\leq 20 \mathrm{ng} / \mathrm{mL}$ ) occurs more frequently among patients with CLD (47-78\%) than in the general population (34-59\%) [12,14-21]. Importantly, vitamin D deficiency causes high mortality in patients with liver cirrhosis (LC), irrespective of the impact of hepatocellular carcinoma [16,22].

Recently, several investigators have focused on the association between $25(\mathrm{OH}) \mathrm{D}$ levels and skeletal muscle function $[23,24]$. Previous studies have demonstrated that low vitamin D levels were related to sarcopenia, frailty, impaired physical performance, and an increased risk of mortality in elderly individuals [25-32]. In addition, a recent study affirmed that low vitamin D levels were associated with sarcopenia in patients with CLD [15]. However, the relationship between 25(OH)D levels, sarcopenia, and frailty in patients with CLD has not yet been reported and thus, remains unknown. Therefore, in the present study, we aimed at exploring the relationship between serum $25(\mathrm{OH}) \mathrm{D}$ levels and the prevalence of sarcopenia and frailty in patients with CLD.

\section{Patients and Methods}

\subsection{Study Design and Patients}

The present cross-sectional study included 231 consecutive patients in whom CLD was diagnosed at Fuji City General Hospital (Shizuoka, Japan) between 2017 and 2020. The inclusion criteria were as follows: (1) the presence of CLD; (2) the availability of data on skeletal muscle mass index (SMI) measured using bioimpedance analysis (InBody S10; InBody, Seoul, Korea), and grip strength using a dynamometer (T.K.K5401 GRIP-D; Takei Scientific Instruments, Niigata, Japan); and (4) the availability of frailty data evaluated based on the diagnostic criteria proposed by Fried et al. [33]. The exclusion criteria were as follows: (1) patients with refractory ascites or implants or undergoing hemodialysis, as previously described [2]; (2) patients with alcoholic liver disease because heavy alcohol consumption frequently leads to malnutrition, including vitamin D deficiency; and (3) patients who had been receiving vitamin D supplementation within 12 months before the date of entry. This study was conducted according to the criteria set by the 2013 revision of the Declaration of Helsinki. The Ethics Committee of Fuji City General Hospital approved this study (approval no. 156).

\subsection{Diagnosis of Sarcopenia and Frailty}

A diagnosis of sarcopenia was made based on the criteria published by the Japan Society of Hepatology [1]. Briefly, sarcopenia was defined as a physical condition with reduced handgrip strength ( $<18 \mathrm{~kg}$ for women and $<26 \mathrm{~kg}$ for men) and muscle mass (SMI $<5.7 \mathrm{~kg} / \mathrm{m}^{2}$ for women and $<7.0 \mathrm{~kg} / \mathrm{m}^{2}$ for men). The SMI was computed from the total muscle mass of the four limbs divided by the square of height $\left(\mathrm{kg} / \mathrm{m}^{2}\right.$ ). Gait speed was measured using the 6-m walk test (low gait speed was defined as $<1.0 \mathrm{~m} / \mathrm{s}$ ). A diagnosis of frailty was made using a validated screening tool based on the following five components [33,34]: (1) weight loss ( $\geq 2 \mathrm{~kg}$ during the last six months); (2) weakness (handgrip strength $<18 \mathrm{~kg}$ for women and $<26 \mathrm{~kg}$ for men); (3) exhaustion, which was determined based on an agreement to the question: "In the last two weeks, have you felt tired without a reason?"; (4) slowness 
(gait speed of $<1.0 \mathrm{~m} / \mathrm{s}$ ); and (5) low physical activity, which was established based on negative answers to the following two questions: "Do you engage in moderate levels of physical exercise or sports aimed at health?" or "Do you engage in low levels of physical exercise aimed at health?". Frailty was determined by three or more agreements [34].

\subsection{Clinical and Laboratory Assessments}

Serum was collected from each patient in an early morning fasting state. The following blood tests were measured using routine, conventional methods: prothrombin time-international normalized ratio (PT-INR), albumin, total bilirubin, and BCAA. The level of serum $25(\mathrm{OH}) \mathrm{D}$, a biomarker of a person's vitamin D status, was measured using a chemiluminescent immunoassay (Hitachi Chemical Diagnostics Systems, Tokyo, Japan). Vitamin D deficiency, insufficiency, and sufficiency were defined as serum $25(\mathrm{OH})$ D levels of $\leq 20.0 \mathrm{ng} / \mathrm{mL}, 20.1-29.9 \mathrm{ng} / \mathrm{mL}$, and $\geq 30.0 \mathrm{ng} / \mathrm{mL}$, respectively, based on the conventional classification of vitamin D status [35].

\subsection{Provisional Reclassification Based on the Serum 25-Hydroxyvitamin D Levels}

The median serum 25(OH)D level for all patients was 14.0 (interquartile range, 10.5-18.1) ng/mL. The patients were reclassified into three groups according to the first and third quartiles (Figure S1): (1) low 25(OH)D (L-VD) group with levels $\leq 10.5 \mathrm{ng} / \mathrm{mL}$ (first quartile); (2) intermediate $25(\mathrm{OH}) \mathrm{D}$ (I-VD) group with levels between 10.5 and $18.1 \mathrm{ng} / \mathrm{mL}$ (third quartile); and (3) high 25(OH)D (H-VD) group with levels $\geq 18.1 \mathrm{ng} / \mathrm{mL}$.

\subsection{Statistics}

Categorical and continuous data are expressed as number (percentage) and median (interquartile range), respectively. The chi-squared test was performed to compare frequencies in categorical data between two groups. The Mann-Whitney $U$ test was performed to compare differences in continuous data between two groups. The Kruskal-Wallis test followed by the Steel-Dwass post hoc test was performed for multiple continuous data comparisons among three groups. Univariate and multiple logistic regression analyses were done to determine significant and independent factors associated with sarcopenia and frailty. The Cochran-Armitage trend test was performed to evaluate whether a trend was present between one variable with two categories and one variable with multiple categories. The Spearman's rank correlation test was used to analyze correlations between two continuous variables. These analyses were done using the SPSS software (ver. 26, IBM, Japan, Tokyo, Japan). A value of $p<0.05$ was considered statistically significant.

\section{Results}

\subsection{Baseline Characteristics of Patients}

The baseline characteristics of the 231 CLD patients in the present study are shown in Table 1. The patients consisted of 95 men (41.1\%) and 136 women (58.9\%), with a median age of $70.0(60.0-76.0)$ years for all patients. Ninety-eight $(42.4 \%)$ patients were diagnosed with LC. The median $25(\mathrm{OH}) \mathrm{D}$ level was $14.0(10.5-18.1) \mathrm{ng} / \mathrm{mL}$. The median values of handgrip strength, SMI, and gait speed were $22.1(17.4-29.4) \mathrm{kg}, 6.30(5.54-7.12) \mathrm{kg} / \mathrm{m}^{2}$, and $1.10(0.91-1.25) \mathrm{m} / \mathrm{s}$, respectively. Eighty-one (35.1\%) patients had slow gait speed. 
Table 1. Baseline clinical characteristics among patients with and without sarcopenia.

\begin{tabular}{|c|c|c|c|c|}
\hline Variable & All Patients & Sarcopenia Group & Non-Sarcopenia Group & $p$ Value \\
\hline Patients, n (\%) & 231 & $66(28.6)$ & $165(71.4)$ & \\
\hline Man, n (\%) & $95(41.1)$ & $23(34.8)$ & $72(43.6)$ & 0.220 \\
\hline Age (years) & $70.0(60.0-76.0)$ & $76.0(72.8-80.3)$ & $68.0(58.0-73.0)$ & $<0.001$ \\
\hline BMI $\left(\mathrm{kg} / \mathrm{m}^{2}\right)$ & $23.1(20.7-26.0)$ & $20.5(19.2-22.6)$ & $24.2(21.8-26.6)$ & $<0.001$ \\
\hline Liver cirrhosis, $\mathrm{n}(\%)$ & $98(42.4)$ & $40(60.6)$ & $58(35.2)$ & $<0.001$ \\
\hline \multicolumn{5}{|l|}{ Etiology } \\
\hline HBV/HCV/PBC/other, $\mathrm{n}$ & $42 / 90 / 60 / 39)$ & $5 / 36 / 19 / 6$ & $37 / 54 / 41 / 33)$ & 0.002 \\
\hline Total bilirubin (mg/dL) & $0.7(0.5-0.9)$ & $0.6(0.5-0.9)$ & $0.7(0.5-0.9)$ & 0.610 \\
\hline Albumin (g/dL) & $4.1(3.9-4.4)$ & $3.9(3.6-4.3)$ & $4.2(3.9-4.4)$ & 0.003 \\
\hline Prothrombin time INR & $1.02(0.96-1.11)$ & $1.05(0.96-1.13)$ & $1.02(0.96-1.10)$ & 0.130 \\
\hline $\mathrm{BCAA}(\mu \mathrm{mol} / \mathrm{L})$ & $408(357-475)$ & $364(302-425)$ & $432(381-488)$ & $<0.001$ \\
\hline $25(\mathrm{OH}) \mathrm{D}(\mathrm{ng} / \mathrm{mL})$ & $14.0(10.5-18.1)$ & $12.2(8.8-15.7)$ & $14.7(11.4-18.4)$ & 0.001 \\
\hline Vitamin D insufficiency, n (\%) & $26(11.3)$ & $4(6.1)$ & $22(13.3)$ & 0.114 \\
\hline Vitamin D deficiency, n (\%) & $201(87.0)$ & $62(93.9)$ & $139(84.2)$ & 0.048 \\
\hline \multicolumn{5}{|l|}{$\operatorname{SMI}\left(\mathrm{kg} / \mathrm{m}^{2}\right)$} \\
\hline All patients & $6.30(5.54-7.12)$ & $5.20(4.82-5.71)$ & $6.75(5.98-7.44)$ & $<0.001$ \\
\hline Man & $7.13(6.48-7.87)$ & $6.18(5.49-6.84)$ & $7.49(7.05-8.15)$ & $<0.001$ \\
\hline Woman & $5.86(5.20-6.44)$ & $5.09(4.67-5.30)$ & $6.05(5.83-6.59)$ & $<0.001$ \\
\hline \multicolumn{5}{|l|}{ Handgrip strength (kg) } \\
\hline All patients & $22.1(17.4-29.4)$ & $16.8(13.8-18.4)$ & $24.5(19.9-32.6)$ & $<0.001$ \\
\hline Man & $30.5(24.1-37.5)$ & $22.8(18.3-24.2)$ & $33.4(28.5-38.9)$ & $<0.001$ \\
\hline Woman & $18.8(15.1-22.5)$ & $15.0(12.8-17.2)$ & $21.3(18.5-24.0)$ & $<0.001$ \\
\hline Gait speed (m/s) & $1.10(0.91-1.25)$ & $0.90(0.68-1.07)$ & $1.15(1.02-1.28)$ & $<0.001$ \\
\hline Slow gait speed, n (\%) & $81(35.1)$ & $49(74.2)$ & $32(19.4)$ & $<0.001$ \\
\hline Frailty, n (\%) & $70(30.3)$ & $51(77.3)$ & $19(11.5)$ & $<0.001$ \\
\hline
\end{tabular}

\subsection{Comparison of Clinical Characteristics among Patients with and without Sarcopenia}

Sixty-six (28.6\%) were diagnosed with sarcopenia among the 231 patients (Table 1$)$. The patients in the sarcopenia group were significantly older and had a lower body mass index (BMI) than those in the non-sarcopenia group ( $p<0.001$ for both). The sarcopenia group had a higher prevalence of LC than the non-sarcopenia group $(60.6 \%$ vs. $35.2 \% ; p<0.001)$. As for the biochemical findings, the levels of albumin $(p=0.003)$, BCAA $(p<0.001)$, and $25(\mathrm{OH}) \mathrm{D}(p=0.001)$ in the sarcopenia group were significantly lower than those in the non-sarcopenia group. Vitamin D deficiency was significantly more frequent in the sarcopenia group than in the non-sarcopenia group $(p=0.048)$. The sarcopenia group showed significantly higher rates of frailty $(77.3 \%$ vs. $11.5 \% ; p<0.001)$ and slow gait speed (74.2\% vs. $19.4 \% ; p<0.001)$ than the non-sarcopenia group.

\subsection{Significant Factors Related to Sarcopenia among Patients with Chronic Liver Disease}

The univariate analysis showed that the following eight variables were significantly associated with sarcopenia: age, BMI, LC, serum levels of albumin, BCAA, and 25(OH)D, PT-INR deficiency vitamin D (Table S1). Finally, the following four variables remained significant and independent on the multivariate analysis (Table 2): advanced age (odds ratio (OR), 1.087; 95\% confidence interval (CI), 1.044-1.130; $p<0.001)$; the presence of LC (OR, 2.493; 95\% CI, 1.180-5.266; $p=0.017)$; lower BMI (OR, 0.720; 95\% CI, 0.635-0.817; $p<0.001)$; and lower 25 (OH)D levels (OR, 0.863; 95\% CI, 0.794-0.937; $p<0.001)$. 
Table 2. Significant factors related to sarcopenia in patients with chronic liver disease.

\begin{tabular}{lcrrr}
\hline \multirow{2}{*}{ Variable } & \multicolumn{2}{c}{ Univariate } & \multicolumn{2}{c}{ Multivariate } \\
\cline { 2 - 5 } & OR (95\% CI) & $p$-Value & OR (95\% CI) & $p$ Value \\
\hline Age $($ years) & $1.083(1.047-1.121)$ & $<0.001$ & $1.087(1.044-1.130)$ & $<0.001$ \\
BMI $\left(\mathrm{kg} / \mathrm{m}^{2}\right)$ & $0.726(0.649-0.813)$ & $<0.001$ & $0.720(0.635-0.817)$ & $<0.001$ \\
Liver cirrhosis & $2.838(1.576-5.111)$ & 0.001 & $2.493(1.180-5.266)$ & 0.017 \\
Albumin $(\mathrm{g} / \mathrm{dL})$ & $0.334(0.184-0.605)$ & $<0.001$ & & \\
Prothrombin time INR & $11.004(1.104-109.651)$ & 0.041 & & \\
BCAA $(\mu \mathrm{mol} / \mathrm{L})$ & $0.992(0.988-0.995)$ & $<0.001$ & & $<0.001$ \\
25(OH)D $(\mathrm{ng} / \mathrm{mL})$ & $0.896(0.841-0.953)$ & 0.001 & $0.863(0.794-0.937)$ & \\
Vitamin D deficiency & $2.899(0.971-8.661)$ & 0.057 & & \\
\hline
\end{tabular}

25(OH)D, 25-hydroxyvitamin D; BCAA, branched-chain amino acid; BMI, body mass index; CI, confidence interval; INR, international normalized ratio; OR, odds ratio.

\subsection{Comparison of Clinical Characteristics among Patients with and without Frailty}

The prevalence rate of frailty was 30.3\% (70/231) (Table S2). The patients with frailty were significantly older and had a higher prevalence of LC (68.6\% vs. $31.1 \%)$ and lower BMI than those without frailty $(p<0.001$ for all). The patients in the frail group had significantly lower levels of $25(\mathrm{OH}) \mathrm{D}(p<0.001)$, albumin $(p<0.001)$, BCAA $(p<0.001)$, and longer PT-INR $(p=0.014)$ than those in the non-frail group. The frail group had significantly higher rates of sarcopenia $(72.9 \% \mathrm{vs.} 9.3 \%$; $p<0.001)$ and slow gait speed $(92.9 \%$ vs. $9.9 \% ; p<0.001)$ than the non-frail group.

\subsection{Significant Factors Related to Frailty among Patients with Chronic Liver Disease}

On the univariate analysis, the following eight variables were significantly related to frailty: age, BMI, LC, serum levels of albumin, BCAA, and 25(OH)D, PT-INR, and vitamin D deficiency (Table S3). The following four variables remained significant and independent on the multivariate analysis (Table 3): advanced age (OR, 1.094; 95\% CI, 1.052-1.138; $p<0.001)$; the presence of LC (OR, $3.749 ; 95 \%$ CI, 1.843-7.626; $p<0.001$ ); lower BCAA levels (OR, 0.994; 95\% CI, 0.990-0.998; $p=0.008$ ); and lower 25(OH)D levels (OR, 0.887; 95\% CI, 0.822-0.957; $p=0.002)$.

Table 3. Significant factors related to frailty in patients with chronic liver disease.

\begin{tabular}{lcrrc}
\hline \multirow{2}{*}{ Variable } & \multicolumn{2}{c}{ Univariate } & \multicolumn{2}{c}{ Multivariate } \\
\cline { 2 - 5 } & \multicolumn{1}{c}{ OR (95\% CI) } & \multicolumn{1}{c}{$\boldsymbol{p}$-Value } & OR (95\% CI) & $p$ Value \\
\hline Age (years) & $1.091(1.054-1.129)$ & $<0.001$ & $1.094(1.052-1.138)$ & $<0.001$ \\
BMI $\left(\mathrm{kg} / \mathrm{m}^{2}\right)$ & $0.869(0.801-0.943)$ & 0.001 & & \\
Liver cirrhosis & $4.844(2.645-8.870)$ & $<0.001$ & $3.749(1.843-7.626)$ & $<0.001$ \\
Albumin $(\mathrm{g} / \mathrm{dL})$ & $0.292(0.159-0.534)$ & $<0.001$ & & \\
Prothrombin time INR & $18.162(1.821-181.168)$ & 0.013 & & 0.008 \\
BCAA $(\mu \mathrm{mol} / \mathrm{L})$ & $0.991(0.988-0.995)$ & $<0.001$ & $0.994(0.990-0.998)$ & 0.002 \\
25(OH)D $(\mathrm{ng} / \mathrm{mL})$ & $0.893(0.840-0.950)$ & 0.001 & $0.887(0.822-0.957)$ & \\
Vitamin D deficiency & $2.390(0.875-6.526)$ & 0.089 & & \\
\hline
\end{tabular}

25(OH)D, 25-hydroxyvitamin D; BCAA, branched-chain amino acid; BMI, body mass index; CI, confidence interval; INR, international normalized ratio; OR, odds ratio.

\subsection{Prevalence of Sarcopenia and Frailty Defined according to the Conventional Classification of Vitamin D Status}

Vitamin D deficiency, insufficiency, and sufficiency were present in 87.0\% (201/231), 11.3\% (26/231), and $1.7 \%(4 / 231)$ of the patients, respectively (Table 1, Figure 1A). The vitamin D deficient group had the highest prevalence of sarcopenia (30.8\% (62/201), Figure 1B) and frailty $(32.3 \%(65 / 201)$, Figure 1C) among the three groups, although the difference was not statistically significant. 


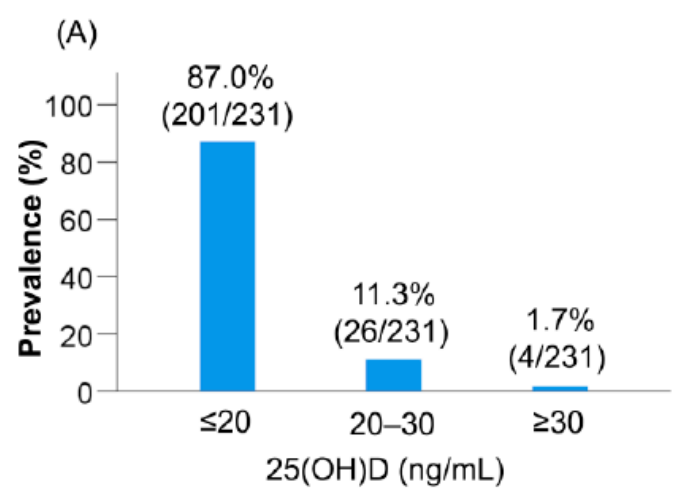

(B)

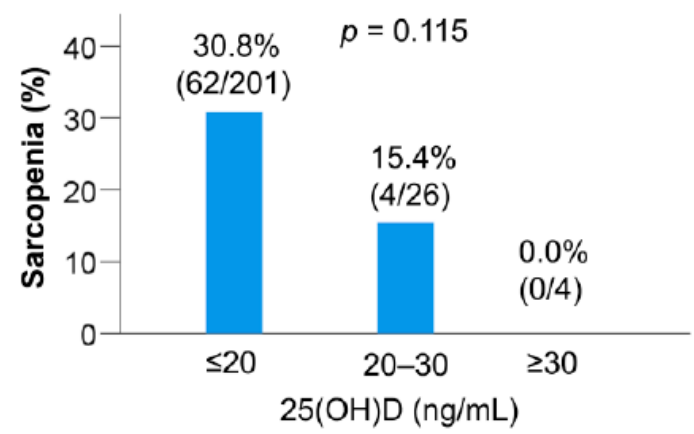

(C)

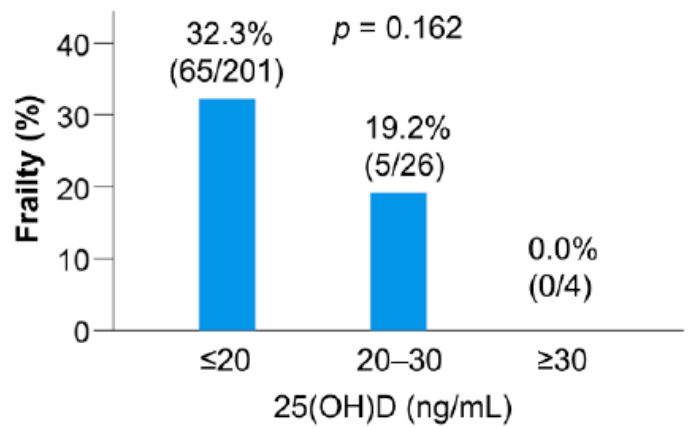

Figure 1. (A) Distribution of the serum 25-hydroxyvitamin D [25(OH)D] levels in patients with chronic liver disease. $(\mathbf{B}, \mathbf{C})$ The prevalence rates of sarcopenia and frailty based on the serum $25(\mathrm{OH}) \mathrm{D}$ levels.

\subsection{Clinical Characteristics Based on the Provisional Reclassification of Vitamin D Status}

As described previously, most patients $(87.0 \%)$ had vitamin D deficiency (as defined by the conventional classification). Therefore, we could not confirm the statistical correlation between vitamin $\mathrm{D}$ deficiency/insufficiency and sarcopenia or frailty. To resolve this issue and explore the association between vitamin D status and disease conditions in more detail, we reclassified the patients into three groups provisionally according to the baseline serum 25(OH)D levels (as described in the Methods section). The distribution of the L-VD, I-VD, and H-VD groups was $24.7 \%(57 / 231), 49.8 \%(115 / 231)$, and $25.5 \%(59 / 231)$, respectively (Table 4$)$. Gender $(p=0.012)$, BCAA $(p<0.001)$, SMI $(p=0.002)$, and handgrip strength $(p<0.001)$ were significantly different among these groups. Notably, the L-VD group had the highest prevalence rate of sarcopenia $(49.1 \%(28 / 57) ; p<0.001$; adjusted residual $=|4.0|)$ and frailty $(49.1 \%(28 / 57) ; p<0.001$; adjusted residual $=|3.6|)$ among these groups, while the H-VD group had the lowest prevalence rate of sarcopenia $(18.6 \%(11 / 59) ; p<0.001$; adjusted residual $=|2.0|)$ and frailty $(15.3 \%(9 / 59) ; p<0.001$; adjusted residual $=|2.9|)($ Table 4, Figure 2A,B). The prevalence rates of sarcopenia and frailty significantly increased in a stepwise manner with a decline in the $25(\mathrm{OH}) \mathrm{D}$ levels $(p<0.001$ for both). 
Table 4. Characteristics of the three groups classified based on the serum 25-hydroxyvitamin D levels.

\begin{tabular}{|c|c|c|c|c|}
\hline Variable & L-VD & M-VD & H-VD & $p$ Value \\
\hline Patients, n (\%) & $57(24.7)$ & $115(49.8)$ & $59(25.5)$ & \\
\hline Man, n (\%) & $20(35.1)$ & $41(35.7)$ & $34(57.6)$ & 0.012 \\
\hline Age (years) & $68.0(55.0-77.0)$ & $70.0(61.0-76.0)$ & $72.0(64.0-77.0)$ & 0.317 \\
\hline $\operatorname{BMI}\left(\mathrm{kg} / \mathrm{m}^{2}\right)$ & $22.2(20.2-26.0)$ & $22.8(20.4-26.1)$ & $23.6(22.3-25.8)$ & 0.489 \\
\hline Liver cirrhosis, n (\%) & $30(52.6)$ & $48(41.7)$ & $20(33.9)$ & 0.122 \\
\hline \multicolumn{5}{|l|}{ Etiology } \\
\hline $\mathrm{HBV} / \mathrm{HCV} / \mathrm{PBC} /$ other, $\mathrm{n}$ & $8 / 21 / 15 / 13$ & 20/50/27/18 & $14 / 19 / 18 / 8$ & 0.499 \\
\hline Total bilirubin (mg/dL) & $0.7(0.5-1.3)$ & $0.6(0.5-0.8)$ & $0.7(0.5-0.9)$ & 0.238 \\
\hline Albumin $(\mathrm{g} / \mathrm{dL})$ & $4.1(3.7-4.5)$ & $4.1(3.8-4.3)$ & $4.2(4.0-4.4)$ & 0.209 \\
\hline Prothrombin time INR & $1.06(0.96-1.16)$ & $1.01(0.95-1.11)$ & $1.00(0.97-1.07)$ & 0.139 \\
\hline $\mathrm{BCAA}(\mu \mathrm{mol} / \mathrm{L})$ & $382(312-432)$ & $420(364-478)$ & $438(379-501)$ & $<0.001$ \\
\hline $25(\mathrm{OH}) \mathrm{D}(\mathrm{ng} / \mathrm{mL})$ & $8.4(6.9-9.7)$ & $14.0(12.4-15.9)$ & $20.1(18.7-23.5)$ & $<0.001$ \\
\hline \multicolumn{5}{|l|}{$\mathrm{SMI}\left(\mathrm{kg} / \mathrm{m}^{2}\right)$} \\
\hline ALL patients & $5.87(5.08-6.96)$ & $6.16(5.66-6.95)$ & $7.04(5.97-7.43)$ & 0.002 \\
\hline Man & 7.07 (6.44-8.27) & $6.98(6.17-7.76)$ & $7.23(7.01-8.11)$ & 0.152 \\
\hline Woman & $5.39(4.87-5.94)$ & $5.97(5.44-6.49)$ & $5.90(5.16-6.70)$ & 0.014 \\
\hline \multicolumn{5}{|l|}{ Handgrip strength $(\mathrm{kg})$} \\
\hline ALL patients & $18.6(14.8-25.1)$ & $22.1(17.8-27.1)$ & $26.9(20.6-33.2)$ & $<0.001$ \\
\hline Man & $26.3(18.3-33.5)$ & $30.2(23.9-37.0)$ & $32.5(27.0-38.9)$ & 0.036 \\
\hline Woman & $17.4(14.1-19.9)$ & $19.1(16.5-22.5)$ & $19.4(16.7-24.0)$ & 0.082 \\
\hline Sarcopenia, n (\%) & $28(49.1)$ & $27(23.5)$ & $11(18.6)$ & $<0.001$ \\
\hline Gait speed $(\mathrm{m} / \mathrm{s})$ & $1.00(0.69-1.16)$ & $1.11(0.92-1.25)$ & $1.17(1.00-1.38)$ & 0.003 \\
\hline Slow gait speed, n (\%) & $29(50.9)$ & $38(33.0)$ & $14(23.7)$ & 0.007 \\
\hline Frailty, n (\%) & $28(49.1)$ & $33(28.7)$ & $9(15.3)$ & $<0.001$ \\
\hline
\end{tabular}

Values are presented as median (interquartile range) or number (percentage). Statistical analysis was carried out using the chi-squared test or the Kruskal-Wallis test, as appropriate. 25(OH)D, 25-hydroxyvitamin D; BCAA, branched-chain amino acid; BMI, body mass index; $\mathrm{HBV}$, hepatitis $B$ virus; $\mathrm{HCV}$, hepatitis $\mathrm{C}$ virus; INR, international normalized ratio; PBC, primary biliary cholangitis; SMI, skeletal muscle mass index.
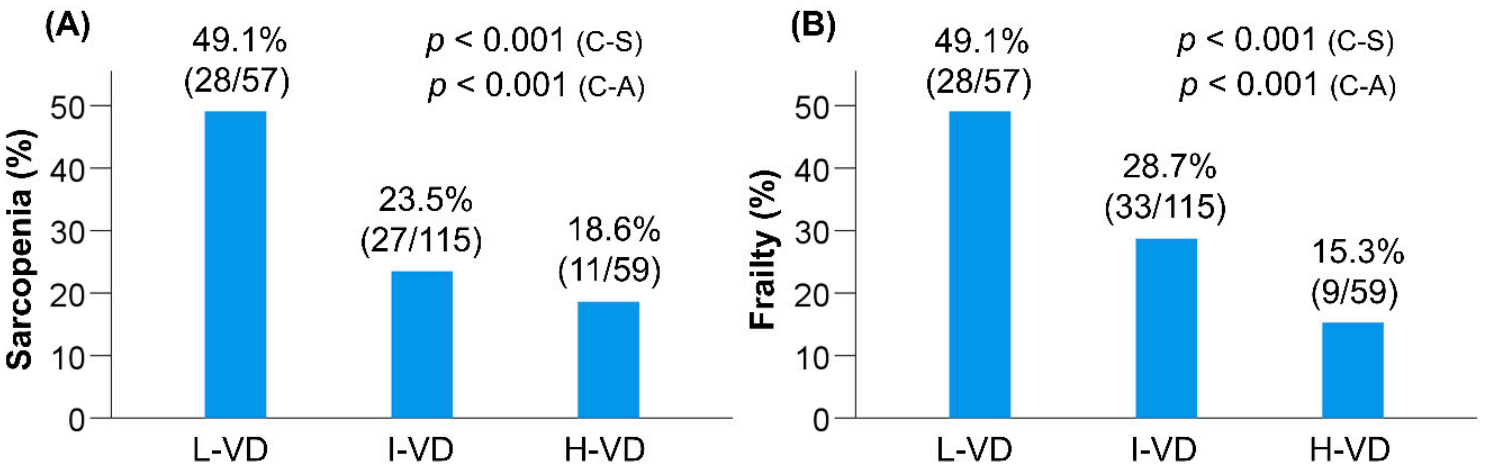

Figure 2. Comparison of clinical characteristics among the low vitamin D (L-VD), intermediate vitamin $\mathrm{D}(\mathrm{I}-\mathrm{VD})$, and high vitamin $\mathrm{D}(\mathrm{H}-\mathrm{VD})$ groups. (A) The L-VD group had the highest prevalence rate of sarcopenia (chi-squared test: $p<0.001$ ), while the H-VD group had the lowest prevalence rate of sarcopenia (chi-squared test: $p<0.001$ ) among the three groups. The prevalence of sarcopenia significantly increased in a stepwise manner with a decline in the serum 25 -hydroxyvitamin $\mathrm{D}$ [25(OH)D] level (Cochran-Armitage trend test: $p<0.001)$. (B) The L-VD group had the highest prevalence rate of frailty (chi-squared test: $p<0.001$ ), while the H-VD group had the lowest prevalence rate of frailty (chi-squared test: $p<0.001$ ) among the three groups. The prevalence of frailty significantly increased in a stepwise manner with a decline in the $25(\mathrm{OH}) \mathrm{D}$ level (Cochran-Armitage trend test: $p<0.001)$. C-A, Cochran-Armitage trend test; C-S, chi-squared test.

\subsection{Correlation between Serum 25(OH)D Levels and Baseline Clinical Characteristics}

The serum 25(OH)D levels correlated significantly with the following baseline factors: BCAA, handgrip strength, SMI, and gait speed. The correlation coefficients for handgrip strength, SMI, 
and gait speed were $0.304(p<0.001), 0.220(p=0.001)$, and $0.251(p<0.001)$, respectively (Figure 3, Table S4).
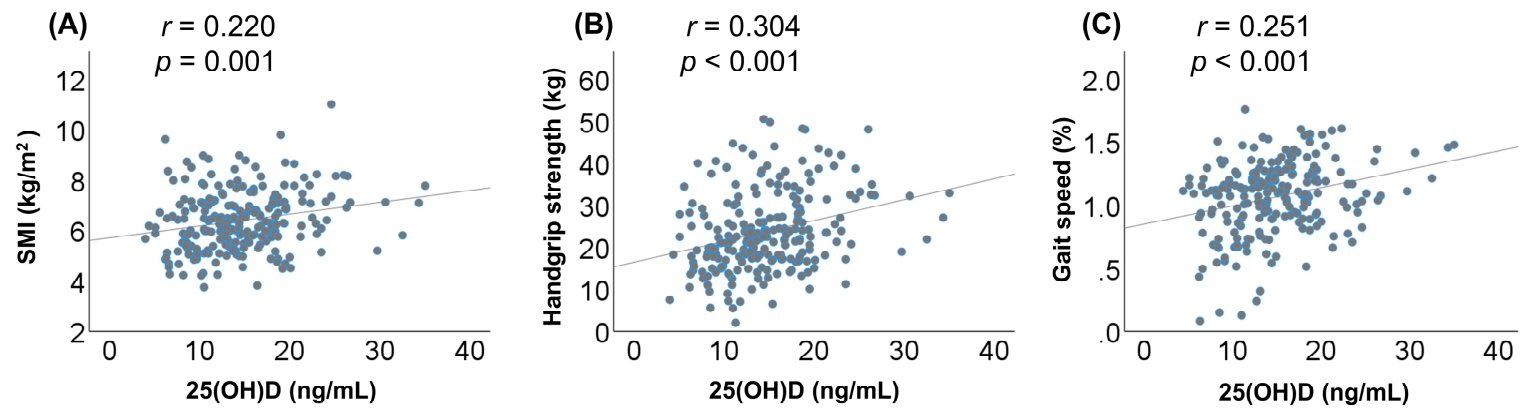

Figure 3. Correlations between the serum 25-hydroxyvitamin D [25(OH)D] levels and skeletal muscle mass index (SMI), handgrip strength, and gait speed in patients with chronic liver disease. The serum 25(OH)D levels were significantly correlated with the (A) SMI $(r=0.220, p=0.001)$, (B) handgrip strength $(r=0.304, p<0.001)$, and $(\mathbf{C})$ gait speed $(r=0.251, p<0.001)$.

\section{Discussion}

Some studies on elderly adults reported that vitamin D deficiency was associated with sarcopenia and impaired physical performance [25-28], while others reported that low vitamin D levels were related to frailty and mortality [29-32]. These results suggest that lower serum vitamin D levels are closely related to frailty and sarcopenia in elderly individuals. However, these relationships have not yet been reported and remain unclear in CLD. In this study, we focused on the relationships between serum vitamin D levels and frailty or sarcopenia in patients with CLD and showed that lower serum $25(\mathrm{OH}) \mathrm{D}$ levels were significantly and independently related to frailty and sarcopenia in such patients.

However, we failed to confirm a statistically significant relationship between the conventional classification of vitamin D status and frailty or sarcopenia, as most patients were vitamin D deficient. Therefore, we provisionally reclassified the patients into three groups based on the serum $25(\mathrm{OH}) \mathrm{D}$ levels and investigated the association between the vitamin $\mathrm{D}$ levels and frailty or sarcopenia. In this reclassification, the cutoff value for the L-VD group $[25(\mathrm{OH}) \mathrm{D} \leq 10.5 \mathrm{ng} / \mathrm{mL}]$ was close to that for patients with "severe" vitamin D deficiency $(\leq 10 \mathrm{ng} / \mathrm{mL}$ or $\leq 12 \mathrm{ng} / \mathrm{mL})[16,36]$. Notably, the L-VD group had the highest prevalence rate of frailty and sarcopenia, while the H-VD group had the lowest prevalence among the three groups. The prevalence of frailty and sarcopenia increased significantly in a stepwise manner with a decline in the vitamin D status. In addition, the $25(\mathrm{OH}) \mathrm{D}$ levels correlated positively and significantly with handgrip strength, SMI, and gait speed. These results suggest that lower serum vitamin D levels, especially severe vitamin D deficient status, are closely related to frailty and sarcopenia in patients with CLD. In addition, the provisional reclassification used in the present study may be useful in clinically treating patients with CLD and frailty and/or sarcopenia.

The vitamin D molecule and vitamin D receptor (VDR) play crucial roles in regulating the musculoskeletal system [24,27,37]. The VDR is expressed in murine and human skeletal muscles, which suggests that vitamin $\mathrm{D}$ has direct effects on muscle tissue [27,38,39]. However, the expression level of VDR declines with increasing age [27]. Mice with vitamin D deficiency and global VDR knockout mice showed reduced muscle mass and strength, and muscle decline progressed with age and an increase in the duration of vitamin D deficiency [40]. In addition, both the mouse models showed significant increases in the expression level of myostatin, a member of the transforming growth factor- $\beta$ family and a negative regulator of muscle protein synthesis [40]. An in vitro study has shown that vitamin $\mathrm{D}$ stimulates myogenic cell differentiation by modulating the expression of pro- and anti-myogenic factors [41].

Skeletal muscle fibers are classified into type I (slow-twitch) and type II (fast-twitch) fibers [27,42]. Type I muscle fibers are characterized by low-power production and high endurance capacity, while type II fibers are characterized by high speed and high strength contractions and are important 
for sprinting exercises [27]. Sarcopenia is characterized by a reduction in the size and proportion of type II fibers [42]. Histological assessment of muscle biopsy specimens from patients with vitamin D deficiency demonstrated a predominance of type II fiber atrophy accompanied by fat cell and glycogen granule infiltration and increased fibrosis [43]. These clinical and basic research findings indicate that both vitamin D deficiency and decreased VDR levels in muscle tissues are associated with sarcopenia and impaired physical performance. Indeed, in the present study, vitamin D deficiency was present in $87.0 \%$ (201/231) of the patients. Notably, approximately half of the patients in the L-VD group had both frailty and sarcopenia. These findings suggest that we must pay more careful attention to patients with severe vitamin D deficiency, especially those with CLD. However, this study did not investigate the expression of VDR in muscle tissues and the association between VDR expression levels and frailty/sarcopenia. Future studies should assess whether the levels of circulating vitamin D and VDR expression in muscle tissues are involved with these complications in patients with CLD.

As described previously, a long period of vitamin D deficiency exacerbates muscle weakness. Therefore, maintaining sufficient vitamin D levels is important to prevent the loss of muscle function [40]. A randomized controlled study of stroke survivors demonstrated that supplementation of vitamin D increased the number and size of type II muscle fibers and improved muscle strength, and consequently, reduced the frequency of falls and hip fractures [44]. Furthermore, vitamin D supplementation for four months increased the expression level of intramyonuclear VDR and the size of muscle fibers in older women with vitamin D insufficiency [45]. A systematic review with meta-analysis reported that daily supplementation of vitamin D improved muscle strength and balance in elderly adults, although its effect on gait was not observed [46]. Another meta-analysis of vitamin D supplementation trials showed positive effects on muscle strength; however, the effect was confined to the lower limbs, and vitamin D supplementation had no impact on muscle mass [47]. Hence, the effects of vitamin D supplementation on skeletal muscle mass and strength are controversial. Considering that sarcopenia has a multifactorial etiology, including nutrition, hormonal status, physical activity, and lifestyle, a comprehensive management strategy, including vitamin D supplementation, physical exercise, and awareness of complications, is required to treat and prevent sarcopenia.

This study has some limitations. First, we did not investigate the nutritional intakes and daily activities, including their exposure to sunlight, which might influence the serum 25(OH)D levels. Second, we did not investigate the mental state (including a depressed mood) and the use of antidepressants, which are associated with impaired physical activity and sarcopenia $[48,49]$. The severity of depression inversely correlates with serum vitamin D levels in patients with CLD [50].

\section{Conclusions}

In this study, we showed that lower serum 25(OH)D levels were significantly and independently related to frailty and sarcopenia in patients with CLD. The prevalence rates of frailty and sarcopenia significantly increased in a stepwise manner with a decline in the vitamin D status (the status was reclassified provisionally). The optimal classification of vitamin D status for patients with CLD may need to be reconsidered to treat those with frailty and/or sarcopenia. Comprehensive assessment (including serum 25(OH)D levels) and early therapeutic interventions (including vitamin D supplementation) are imperative, especially for patients with CLD and severe vitamin D deficiency. 
Supplementary Materials: The following are available online at http://www.mdpi.com/2072-6643/12/12/3810/s1, Figure S1: Classification based on the baseline serum 25-hydroxyvitamin D levels, Table S1: Univariate analysis for significant factors related to sarcopenia, Table S2: Comparison of clinical characteristics among patients with and without frailty, Table S3: Univariate analysis for significant factors related to frailty, Table S4: Correlations between 25-hydroxyvitamin D concentrations and baseline characteristics.

Author Contributions: C.S. participated in the conception and design of the study. C.S., T.K., M.N., and Y.T. acquired, analyzed, and interpreted the data. C.S. and A.T. drafted the manuscript. T.O., M.S., and A.T. interpreted the data and revised the manuscript. A.T. substantively revised and completed the manuscript. All authors read and approved the final version of the manuscript.

Funding: This research received no external funding.

Acknowledgments: We thank the medical staff at Fuji City General Hospital who were involved in the collection of the data.

Conflicts of Interest: The authors declare no conflict of interest.

\section{References}

1. Nishikawa, H.; Shiraki, M.; Hiramatsu, A.; Moriya, K.; Hino, K.; Nishiguchi, S. Japan Society of Hepatology guidelines for sarcopenia in liver disease (1st edition): Recommendation from the working group for creation of sarcopenia assessment criteria. Hepatol. Res. 2016, 46, 951-963. [CrossRef] [PubMed]

2. Saeki, C.; Takano, K.; Oikawa, T.; Aoki, Y.; Kanai, T.; Takakura, K.; Nakano, M.; Torisu, Y.; Sasaki, N.; Abo, M.; et al. Comparative assessment of sarcopenia using the JSH, AWGS, and EWGSOP2 criteria and the relationship between sarcopenia, osteoporosis, and osteosarcopenia in patients with liver cirrhosis. BMC Musculoskelet. Disord. 2019, 20, 615. [CrossRef] [PubMed]

3. Clegg, A.; Young, J.; Iliffe, S.; Rikkert, M.O.; Rockwood, K. Frailty in elderly people. Lancet 2013, 38, 752-762. [CrossRef]

4. Saeki, C.; Kanai, T.; Nakano, M.; Oikawa, T.; Torisu, Y.; Abo, M.; Saruta, M.; Tsubota, A. Relationship between Osteosarcopenia and Frailty in Patients with Chronic Liver Disease. J. Clin. Med. 2020, 26, 2381. [CrossRef] [PubMed]

5. Bhanji, R.A.; Narayanan, P.; Moynagh, M.R.; Takahashi, N.; Angirekula, M.; Kennedy, C.C.; Mara, K.C.; Dierkhising, R.A.; Watt, K.D. Differing Impact of Sarcopenia and Frailty in Nonalcoholic Steatohepatitis and Alcoholic Liver Disease. Liver Transpl. 2019, 25, 14-24. [CrossRef]

6. Tsekoura, M.; Kastrinis, A.; Katsoulaki, M.; Billis, E.; Gliatis, J. Sarcopenia and Its Impact on Quality of Life. Adv. Exp. Med. Biol. 2017, 987, 213-218.

7. Hanai, T.; Shiraki, M.; Nishimura, K.; Ohnishi, S.; Imai, K.; Suetsugu, A.; Takai, K.; Shimizu, M.; Moriwaki, H. Sarcopenia impairs prognosis of patients with liver cirrhosis. Nutrition 2015, 31, 193-199. [CrossRef]

8. Lai, J.C.; Covinsky, K.E.; Dodge, J.L.; Boscardin, W.J.; Segev, D.L.; Roberts, J.P.; Feng, S. Development of a novel frailty index to predict mortality in patients with end-stage liver disease. Hepatology 2017, 66, 564-574. [CrossRef]

9. Lai, J.C.; Rahimi, R.S.; Verna, E.C.; Kappus, M.R.; Dunn, M.A.; McAdams DeMarco, M.; Haugen, C.E.; Volk, M.L.; Duarte-Rojo, A.; Ganger, D.R.; et al. Frailty Associated With Waitlist Mortality Independent of Ascites and Hepatic Encephalopathy in a Multicenter Study. Gastroenterology 2019, 156, 1675-1682. [CrossRef]

10. Cruz-Jentoft, A.J.; Kiesswetter, E.; Drey, M.; Sieber, C.C. Nutrition, frailty, and sarcopenia. Aging Clin. Exp. Res. 2017, 29, 43-48. [CrossRef]

11. Bloom, I.; Shand, C.; Cooper, C.; Robinson, S.; Baird, J. Diet Quality and Sarcopenia in Older Adults: A Systematic Review. Nutrients 2018, 10, 308. [CrossRef] [PubMed]

12. Arteh, J.; Narra, S.; Nair, S. Prevalence of vitamin D deficiency in chronic liver disease. Dig. Dis. Sci. 2010, 55, 2624-2628. [CrossRef] [PubMed]

13. Nakchbandi, I.A. Osteoporosis and fractures in liver disease: Relevance, pathogenesis and therapeutic implications. World J. Gastroenterol. 2014, 20,9427-9438. [PubMed]

14. Konstantakis, C.; Tselekouni, P.; Kalafateli, M.; Triantos, C. Vitamin D deficiency in patients with liver cirrhosis. Ann. Gastroenterol. 2016, 29, 297-306. [CrossRef]

15. Okubo, T.; Atsukawa, M.; Tsubota, A.; Yoshida, Y.; Arai, T.; Iwashita, A.N.; Itokawa, N.; Kondo, C.; Iwakiri, K. Relationship between serum vitamin D level and sarcopenia in chronic liver disease. Hepatol. Res. 2020, 50, 588-597. [CrossRef] 
16. Buonomo, A.R.; Scotto, R.; Zappulo, E.; Nerilli, M.; Pinchera, B.; Perruolo, G.; Formisano, P.; Nappa, S.; Gentile, I. Severe Vitamin D Deficiency Increases Mortality Among Patients With Liver Cirrhosis Regardless of the Presence of HCC. In Vivo 2019, 33, 177-182. [CrossRef]

17. Atsukawa, M.; Tsubota, A.; Shimada, N.; Yoshizawa, K.; Abe, H.; Asano, T.; Ohkubo, Y.; Araki, M.; Ikegami, T.; Kondo, C.; et al. Influencing factors on serum 25-hydroxyvitamin D3 levels in Japanese chronic hepatitis C patients. BMC Infect. Dis. 2015, 15, 344. [CrossRef]

18. Aspell, N.; Laird, E.; Healy, M.; Shannon, T.; Lawlor, B.; O'Sullivan, M. The Prevalence and Determinants of Vitamin D Status in Community-Dwelling Older Adults: Results from the English Longitudinal Study of Ageing (ELSA). Nutrients. 2019, 11, 1253. [CrossRef]

19. Nakamura, K.; Tsugawa, N.; Saito, T.; Ishikawa, M.; Tsuchiya, Y.; Hyodo, K.; Maruyama, K.; Oshiki, R.; Kobayashi, R.; Nashimoto, M.; et al. Vitamin D status, bone mass, and bone metabolism in home-dwelling postmenopausal Japanese women: Yokogoshi Study. Bone 2008, 42, 271-277. [CrossRef]

20. Cashman, K.D.; Dowling, K.G.; Škrabáková, Z.; Gonzalez-Gross, M.; Valtueña, J.; De Henauw, S.; Moreno, L.; Damsgaard, C.T.; Michaelsen, K.F.; Mølgaard, C.; et al. Vitamin D deficiency in Europe: Pandemic? Am. J. Clin. Nutr. 2016, 103, 1033-1044. [CrossRef]

21. Liu, X.; Baylin, A.; Levy, P.D. Vitamin D deficiency and insufficiency among US adults: Prevalence, predictors and clinical implications. Br. J. Nutr. 2018, 119, 928-936. [CrossRef] [PubMed]

22. Paternostro, R.; Wagner, D.; Reiberger, T.; Mandorfer, M.; Schwarzer, R.; Ferlitsch, M.; Trauner, M.; Peck-Radosavljevic, M.; Ferlitsch, A. Low 25-OH-vitamin D levels reflect hepatic dysfunction and are associated with mortality in patients with liver cirrhosis. Wien. Klin. Wochenschr. 2017, 29, 8-15. [CrossRef] [PubMed]

23. Granic, A.; Hill, T.R.; Davies, K.; Jagger, C.; Adamson, A.; Siervo, M.; Kirkwood, T.B.; Mathers, J.C.; Sayer, A.A. Vitamin D Status, Muscle Strength and Physical Performance Decline in Very Old Adults: A Prospective Study. Nutrients 2017, 9, 379. [CrossRef] [PubMed]

24. Wintermeyer, E.; Ihle, C.; Ehnert, S.; Stöckle, U.; Ochs, G.; de Zwart, P.; Flesch, I.; Bahrs, C.; Nussler, A.K. Crucial Role of Vitamin D in the Musculoskeletal System. Nutrients 2016, 8, 319. [CrossRef]

25. Kim, M.K.; Baek, K.H.; Song, K.H.; Il Kang, M.; Park, C.Y.; Lee, W.Y.; Oh, K.W. Vitamin D deficiency is associated with sarcopenia in older Koreans, regardless of obesity: The Fourth Korea National Health and Nutrition Examination Surveys (KNHANES IV) 2009. J. Clin. Endocrinol. Metab. 2011, 96, 3250-3256. [CrossRef]

26. Houston, D.K.; Tooze, J.A.; Davis, C.C.; Chaves, P.H.; Hirsch, C.H.; Robbins, J.A.; Arnold, A.M.; Newman, A.B.; Kritchevsky, S.B. Serum 25-hydroxyvitamin D and physical function in older adults: The Cardiovascular Health Study All Stars. J. Am. Geriatr Soc. 2011, 59, 1793-1801. [CrossRef]

27. Remelli, F.; Vitali, A.; Zurlo, A.; Volpato, S. Vitamin D Deficiency and Sarcopenia in Older Persons. Nutrients 2019, 11, 2861. [CrossRef]

28. Tieland, M.; Brouwer-Brolsma, E.M.; Nienaber-Rousseau, C.; van Loon, L.J.; De Groot, L.C. Low vitamin D status is associated with reduced muscle mass and impaired physical performance in frail elderly people. Eur. J. Clin. Nutr. 2013, 67, 1050-1055. [CrossRef]

29. Wilhelm-Leen, E.R.; Hall, Y.N.; Deboer, I.H.; Chertow, G.M. Vitamin D deficiency and frailty in older Americans. J. Intern. Med. 2010, 268, 171-180. [CrossRef]

30. Vaes, A.M.M.; Brouwer-Brolsma, E.M.; Toussaint, N.; de Regt, M.; Tieland, M.; van Loon, L.J.C.; de Groot, L.C. The association between 25-hydroxyvitamin D concentration, physical performance and frailty status in older adults. Eur. J. Nutr. 2019, 58, 1173-1181. [CrossRef]

31. Wong, Y.Y.; McCaul, K.A.; Yeap, B.B.; Hankey, G.J.; Flicker, L. Low vitamin D status is an independent predictor of increased frailty and all-cause mortality in older men: The Health in Men Study. J. Clin. Endocrinol. Metab. 2013, 98, 3821-3828. [CrossRef] [PubMed]

32. Smit, E.; Crespo, C.J.; Michael, Y.; Ramirez-Marrero, F.A.; Brodowicz, G.R.; Bartlett, S.; Andersen, R.E. The effect of vitamin $\mathrm{D}$ and frailty on mortality among non-institutionalized US older adults. Eur. J. Clin. Nutr. 2012, 66, 1024-1028. [CrossRef] [PubMed]

33. Fried, L.P.; Tangen, C.M.; Walston, J.; Newman, A.B.; Hirsch, C.; Gottdiener, J.; Seeman, T.; Tracy, R.; Kop, W.J.; Burke, G.; et al. Cardiovascular Health Study Collaborative Research Group. Frailty in older adults: Evidence for a phenotype. J. Gerontol. A Biol. Sci. Med. Sci. 2001; 5, M146-M156. 
34. Tsutsumimoto, K.; Doi, T.; Makizako, H.; Hotta, R.; Nakakubo, S.; Makino, K.; Suzuki, T.; Shimada, H. Aging-related anorexia and its association with disability and frailty. J. Cachexia Sarcopenia Muscle 2018, 9, 834-843. [CrossRef] [PubMed]

35. Holick, M.F.; Binkley, N.C.; Bischoff-Ferrari, H.A.; Gordon, C.M.; Hanley, D.A.; Heaney, R.P.; Murad, M.H.; Weaver, C.M. Evaluation, treatment, and prevention of vitamin D deficiency: An Endocrine Society clinical practice guideline. J. Clin. Endocrinol. Metab. 2011, 96, 1911-1930. [CrossRef]

36. Amrein, K.; Scherkl, M.; Hoffmann, M.; Neuwersch-Sommeregger, S.; Köstenberger, M.; Berisha, A.T.; Martucci, G.; Pilz, S.; Malle, O. Vitamin D deficiency 2.0: An update on the current status worldwide. Eur. J. Clin. Nutr. 2020, 20, 1-16. [CrossRef]

37. Pojednic, R.M.; Ceglia, L. The emerging biomolecular role of vitamin D in skeletal muscle. Exerc. Sport Sci. Rev. 2014, 42, 76-81. [CrossRef]

38. Girgis, C.M.; Mokbel, N.; Cha, K.M.; Houweling, P.J.; Abboud, M.; Fraser, D.R.; Mason, R.S.; Clifton-Bligh, R.J.; Gunton, J.E. The vitamin D receptor (VDR) is expressed in skeletal muscle of male mice and modulates 25-hydroxyvitamin D (25OHD) uptake in myofibers. Endocrinology 2014, 155, 3227-3237. [CrossRef]

39. Pojednic, R.M.; Ceglia, L.; Olsson, K.; Gustafsson, T.; Lichtenstein, A.H.; Dawson-Hughes, B.; Fielding, R.A. Effects of 1,25-dihydroxyvitamin D3 and vitamin D3 on the expression of the vitamin d receptor in human skeletal muscle cells. Calcif. Tissue Int. 2015, 96, 256-263. [CrossRef]

40. Girgis, C.M.; Cha, K.M.; Houweling, P.J.; Rao, R.; Mokbel, N.; Lin, M.; Clifton-Bligh, R.J.; Gunton, J.E. Vitamin D Receptor Ablation and Vitamin D Deficiency Result in Reduced Grip Strength, Altered Muscle Fibers, and Increased Myostatin in Mice. Calcif. Tissue Int. 2015, 97, 602-610. [CrossRef]

41. Garcia, L.A.; King, K.K.; Ferrini, M.G.; Norris, K.C.; Artaza, J.N. 1,25(OH)2vitamin D3 stimulates myogenic differentiation by inhibiting cell proliferation and modulating the expression of promyogenic growth factors and myostatin in C2C12 skeletal muscle cells. Endocrinology 2011, 152, 2976-2986. [CrossRef]

42. Talbot, J.; Maves, L. Skeletal muscle fiber type: Using insights from muscle developmental biology to dissect targets for susceptibility and resistance to muscle disease. Wiley Interdiscip. Rev. Dev. Biol. 2016, 5, 518-534. [CrossRef] [PubMed]

43. Ceglia, L.; Harris, S.S. Vitamin D and its role in skeletal muscle. Calcif. Tissue Int. 2013, 92, 151-162. [CrossRef] [PubMed]

44. Sato, Y.; Iwamoto, J.; Kanoko, T.; Satoh, K. Low-dose vitamin D prevents muscular atrophy and reduced falls and hip fractures in women after stroke: A randomized controlled trial. Cerebrovasc. Dis. 2005, 20, 187-192, Retracted in Cerebrovasc. Dis. 2017, 44, 240. [CrossRef] [PubMed]

45. Ceglia, L.; Niramitmahapanya, S.; da Silva Morais, M.; Rivas, D.A.; Harris, S.S.; Bischoff-Ferrari, H.; Fielding, R.A.; Dawson-Hughes, B. A randomized study on the effect of vitamin $\mathrm{D}_{3}$ supplementation on skeletal muscle morphology and vitamin D receptor concentration in older women. J. Clin. Endocrinol. Metab. 2013, 98, E1927-E1935. [CrossRef] [PubMed]

46. Muir, S.W.; Montero-Odasso, M. Effect of vitamin D supplementation on muscle strength, gait and balance in older adults: A systematic review and meta-analysis. J. Am. Geriatr. Soc. 2011, 59, 2291-2300. [CrossRef]

47. Beaudart, C.; Buckinx, F.; Rabenda, V.; Gillain, S.; Cavalier, E.; Slomian, J.; Petermans, J.; Reginster, J.Y.; Bruyère, $\mathrm{O}$. The effects of vitamin $\mathrm{D}$ on skeletal muscle strength, muscle mass, and muscle power: A systematic review and meta-analysis of randomized controlled trials. J. Clin. Endocrinol. Metab. 2014, 99, 4336-4345. [CrossRef]

48. Nishikawa, H.; Enomoto, H.; Yoh, K.; Iwata, Y.; Sakai, Y.; Kishino, K.; Ikeda, N.; Takashima, T.; Aizawa, N.; Takata, R.; et al. Association between Sarcopenia and Depression in Patients with Chronic Liver Diseases. J. Clin. Med. 2019, 8, 634. [CrossRef]

49. An, R.; Lu, L. Antidepressant use and functional limitations in U.S. older adults. J. Psychosom. Res. 2016, 80, 31-36. [CrossRef] 
50. Stokes, C.S.; Grünhage, F.; Baus, C.; Volmer, D.A.; Wagenpfeil, S.; Riemenschneider, M.; Lammert, F. Vitamin D supplementation reduces depressive symptoms in patients with chronic liver disease. Clin. Nutr. 2016, 35, 950-957. [CrossRef]

Publisher's Note: MDPI stays neutral with regard to jurisdictional claims in published maps and institutional affiliations.

(C) 2020 by the authors. Licensee MDPI, Basel, Switzerland. This article is an open access article distributed under the terms and conditions of the Creative Commons Attribution (CC BY) license (http://creativecommons.org/licenses/by/4.0/). 